\title{
In the Big Red Desert of Political Slavery
}

Nicholas McKay

The mediocrity of society

has reached a triple figure percentage, and for those of us who have been sleepwalking through life, the darkness has become all but impenetrable the moment we wake up.

Beyond the belief of intellect's scope, the damages wrought upon the social mainframe have reduced what was once proud and boastful, to the rubble we call our home; buildings built on the layers of lies, writ my masochistic villainy. The honourable leadership of past structures has succumb 
to temptation and duress,

the seductive touch of sinful economics, and the antagonistic pull

of corruption turning our nation into ash, until it is incapable of recognition. The directionality and scope of life's shit overture prohibits the existence of beauty, as blossoming futility causes all to surrender beneath the reign of inevitable slavery, for that is all we ever are. We pay; we eat; we fuck; we sleep, but all the while underneath the gaze of governmental employees, whose expertise in stock management ensures we never exhibit too much fun. With this thought penned upon the page, is leniency from political threat really too much to ask, or are we doomed to suffer as submissive tools of oppressive bodies until our life force wanes and our money runs dry like the desert? 